\title{
Hemicraniectomy for Massive Middle Cerebral Artery Infarction: A Review
}

\author{
Dulka Manawadu, Ahmed Quateen, J. Max Findlay
}

\begin{abstract}
Hemicraniectomy and opening underlying dura mater permits the expansion of infarcted, swollen brain outwards, reversing dangerous intracranial pressure elevations and the risk of fatal transtentorial temporal lobe or diencephalic herniation. Recently published randomized controlled trials have proven this procedure a powerful life-saving measure in the setting of malignant middle cerebral artery infarction and allayed concerns that a reduction in mortality is accompanied by an unacceptable increase in patients suffering severe neurological impairments. Appropriate patients are relatively young, in the first five decades of life, suffering infarction of a majority of the middle cerebral artery (MCA) territory in either hemisphere, and decompression should be performed prior to progression to coma or two dilated, fixed pupils. Lethargy combined with midline shift and uncal herniation on neuroimaging is an appropriate trigger to consider and discuss surgical intervention. Families and, when possible, patients themselves, should be informed of the certainty of at least moderate to mild permanent deficits, and the possibility of worse. To be successful decompression must be extensive, targeting a bone flap measuring $14 \mathrm{~cm}$ from front to back, and extending 1 to $2 \mathrm{cms}$ lateral to the midline sagittal suture to the floor of the middle cranial fossa at the level of the coronal suture. An augmentation duraplasty is mandatory.
\end{abstract}

RÉSUMÉ: Revue de l'hémicrâniectomie dans l'infarctus massif de l'artère cérébrale moyenne. L'hémicrâniectomie et l'ouverture de la dure-mère sous-jacente permettent l'expansion du cerveau infarcisé et oedématié, diminuant ainsi la pression intracrânienne et le risque de hernie transtentorielle temporale ou diencéphalique fatale. Des études randomisées, contrôlées, publiées récemment ont montré que cette procédure était un outil puissant pour sauver la vie dans le contexte d'un infarctus massif du territoire de l'artère cérébrale moyenne (ACM) et dissiper la crainte qu'une diminution de la mortalité ne soit accompagnée par une augmentation inacceptable de déficits neurologiques sévères chez ces patients. Les patients qui peuvent en bénéficier sont relativement jeunes, soit dans les cinq premières décennies de vie et présentent un infarctus de la majorité du territoire de l'ACM de l'un ou l'autre hémisphère. La décompression devrait être effectuée avant que le patient ne soit dans le coma ou que ses deux pupilles ne soient dilatées et fixes. La léthargie associée à un déplacement médian et une hernie de l'uncus à la neuroimagerie sont des signaux indiquant qu'on doit envisager cette intervention et en discuter. La famille et le patient lui-même si possible devraient être informés de la certitude de déficits permanents de légers à modérés ou pire. La décompression doit être extensive pour être efficace. Le volet osseux doit mesurer $14 \mathrm{~cm}$ d'avant en arrière et s'étendre latéralement de 1 à $2 \mathrm{~cm}$ de la suture sagittale médiane jusqu'au plancher de la fosse cérébrale moyenne au niveau de la suture coronale. Une plastie durale d'augmentation est essentielle.

Can. J. Neurol. Sci. 2008; 35: 544-550

Middle cerebral artery (MCA) occlusion and territory infarction causes hemiplegia, gaze deviation, aphasia when the dominant hemisphere is involved and neglect of the paralyzed limbs when it is not. Consciousness typically deteriorates over several days as cytotoxic edema worsens, intracranial pressure builds, and global cerebral perfusion becomes increasingly compromised. ${ }^{1}$ Especially in younger patients without preexisting cerebral atrophy, these "malignant" MCA infarctions lead to uncal herniation and death in as many as $80 \%$ of sufferers. $^{2}$

As reviewed by Ivamoto et $\mathrm{al}^{3}{ }^{3}$ and more recently Robertson et al, ${ }^{4}$ surgery to remove a portion of skull (craniectomy) and excise necrotic brain tissue in order to prevent fatal brain uncal or diencephalic herniation has been described in case reports and small patient series dating as far back as 1935. The size of skull openings has varied, as has the extent of brain resection and use of a dural patch (duraplasty) to allow for additional brain swelling. "Hemicraniectomy" without concomitant resection of infarcted brain was first described by Rengachary et al in 1981,5 all three of their patients survived, two with severe disability and one with moderate deficits. While apparently life saving on occasion, the major concern regarding decompressive surgery for cerebral infarction was that any reduction in mortality would

\footnotetext{
From the Division of Neurology, Division of Neurosurgery, Faculty of Medicine, University of Alberta, Edmonton, Alberta, Canada.

ReCEIVEd ApRil 7, 2008. Final ReVISIONS Submitted May 12, 2008. Correspondence to: J. Max Findlay, Rm. 2D 102 Mackenzie Centre, University Hospital, 8440112 Street, Edmonton, Alberta T6G 2B7
} 
result in an unacceptable increase in the number of patients surviving with severe neurological deficits requiring long-term care.

In 1995 and 1998 the largest series of patients undergoing decompression for MCA stroke was reported by the group at the University of Heidelberg. ${ }^{6,7}$ In the larger of the two overlapping series consisting of 68 patients, it was found that hemicraniectomy and duraplasty was associated with a strikingly lower mortality rate $(27 \%)$ than during the natural history of malignant MCA infarction (78\%) observed in 55 contemporaneous patients, ${ }^{8}$ along with what appeared to be reasonable recoveries in the surgical group. They had a range of disabilities but none were left permanently wheelchair dependent and none of the 11 patients with dominant hemisphere strokes remained globally aphasic. The authors stressed that to be effective surgery had to be extensive. This favourable experience renewed interest in decompressive surgery for MCA stroke, with additional case series subsequently reported from around the world. A systematic review published in 2004 found 12 studies of hemicraniectomy for MCA infarction suitable for a combined analysis, and after adding nine patients from the authors' own institution there was a total of 138 patients included. ${ }^{9}$ It was found that $80 \%$ of the 75 patients over the age of 50 died or were severely disabled following surgery, compared with $32 \%$ of 63 patients 50 years of age or younger. There also appeared to be a clear indication in this review that, at least in younger patients, decompressive surgery could leave many survivors with moderate, as opposed to severe, neurological deficits. The stage was set for randomized trials. ${ }^{10,11}$

\section{Randomized trials of hemicraniectomy for MCA infarction}

The first randomized trial of hemicraniectomy for malignant MCA infarction was halted in the United States in 2003 due to slow recruitment (only 26 patients in three years). ${ }^{12}$ Three European randomized controlled trials were also initiated, two were subsequently stopped, with published results ${ }^{13,14}$ and one is still ongoing. ${ }^{15}$ A preplanned pooled analysis of all three of these trials was published last year. ${ }^{16}$ Decompressive Surgery for the Treatment of Malignant Infarction of the Middle Cerebral Artery (DESTINY), one of the two discontinued studies, began enrollment in early 2004. Eligible patients were aged 18 to 60 years with infarcts involving more than two-thirds of the MCA territory, causing hemiplegia and drowsiness but excluding comatose patients (Glasgow Coma Scale < 6) and those with fixed, dilated pupils. ${ }^{13}$ Patients were operated on within 36 hours of symptom onset. Thirty-day mortality was $53 \%$ in the medical arm compared to $12 \%$ of those who underwent hemicraniectomy, and after one year, surgery resulted in a near doubling of the rate of favourable (primary) outcome as defined by a modified Rankin scale (mRS) of 3 or less. ${ }^{17}$ Only 32 patients were included before the study was terminated because of the large reduction in mortality provided by hemicraniectomy, but the inclusion of only 32 patients did not allow a statistically significant difference in the primary end point. It was hoped that the planned pooled analysis would have sufficient power to shed some light on neurological outcomes.

The other trial terminating early was Decompressive Craniectomy in Malignant MCA Infarction (DECIMAL) Trial which had an upper age limit of 55 years and required diffusion weighted MRI imaging to establish an infarct volume of greater than $145 \mathrm{~cm}^{3}$ for inclusion into the study. ${ }^{14}$ This was also stopped because of slow recruitment (38 patients between 2001 and 2005), as well as the knowledge that the preplanned pooled analysis of the three European studies was imminent. DECIMAL showed that hemicraniectomy provided a five fold increase in minimal disability $(\mathrm{mRS} \leq 3)$ at six months as compared with no surgery although once more, small numbers prevented this primary outcome result from being statistically significant. The third trial, Hemicraniectomy after middle cerebral artery infarction with life-threatening Edema trial (HAMLET) has similar inclusion criteria to DESTINY but was still on going at the time of pooled analysis and its individual results have not yet been published..$^{15}$

In total, 93 patients from the three similar European trials were included in the pooled analysis. ${ }^{16}$ The primary outcome measure was a dichotomized favorable $(\mathrm{mRS} \leq 4)$ or unfavorable (mRS 5 and 6) outcome at one year. Secondary outcomes were fatality rates and dichotomizated mRS scores between 0-3 and 46 at one year, the latter to examine if surgery can result in survival without severe disability. The combined results from the three studies showed that three times as many people achieved the favorable primary outcome in the decompressive surgery group $(75 \%)$ than in the conservative treatment group $(24 \%)$. If applicable to real world clinical practice, this absolute increase of $51 \%$ in achievement of primary outcome indicates that as many as every second patient undergoing hemicraniectomy for malignant MCA infarction, will benefit. Hemicraniectomy also reduced mortality from $71 \%$ to $22 \%$, corresponding to an absolute reduction in risk of death of $49 \%$ and similarly suggests that in practice, only two patients require surgery to save one life. The other secondary outcome measure was linked to quality of life, allowing less severe levels of disability into the "favourable" outcome group, so that the ability to walk independently despite requiring help for daily activities (mRS 3) would be the "worst case" scenario. This outcome was achieved in twice the number of patients randomized to surgery $(43 \%)$ than to conservative treatment $(21 \%)$, with an absolute increase of $23 \%$ suggesting that four patients need to be operated on to achieve this outcome in one. These results help dispel concerns that decompressive surgery following middle cerebral artery infarction risks outcomes of severe neurological disability with complete dependence on others. Patients can experience reasonable outcomes from decompression depending, of course, upon individual values and choice. The Table summarizes findings from the pooled analysis.

In a recent editorial, Stephan Mayer suggests we discuss with patients and their families the real implications of the trials to date. ${ }^{18}$ Based on the pooled analysis ${ }^{16}$ he calculated that for every ten patients undergoing decompression, five will be saved from death, three of whom will be left unable to walk alone and require help from others with activities of daily living, one able to walk independently albeit with a brace and/or cane, but requiring help for daily living, and one will have only a mild disability, not needing help but still having to relinquish a usual activity. In other words, the odds are a reasonable to good outcome in two of five saved by surgery. It must be pointed out again though that the definition of a favourable outcome from the pooled analysis ${ }^{16}$ still included those who were moderately 
Table: Summary of results from the pooled analysis of the randomized, controlled studies DESTINY, DECIMAL and HAMLET ${ }^{13-15}$

\begin{tabular}{lllll}
\hline mRS & Functional description & Hemicraniectomy (\%) & Conservative (\%) & Absolute risk change (\%) \\
6 & Dead & 22 & 71 & $49 \downarrow$ \\
5 & $\begin{array}{l}\text { Severe disability, total dependence } \\
\text { for care upon others }\end{array}$ & 4 & 5 & $1 \downarrow$ \\
4 & $\begin{array}{l}\text { Moderately severe disability, requiring } \\
\text { help with ADLs and inability to } \\
\text { walk without assistance }\end{array}$ & 31 & 2 & $19 \uparrow$ \\
3 & $\begin{array}{l}\text { Moderate disability, requiring help with } \\
\text { ADLs but able to walk without assistance }\end{array}$ & 29 & 19 & $10 \uparrow$ \\
2 & $\begin{array}{l}\text { Slight disability, unable to carry out all } \\
\text { previous activities but remains independent }\end{array}$ & 14 & 2 & $12 \uparrow$ \\
\hline
\end{tabular}

$\mathrm{mRS}=$ modified Rankin scale; ADLs=activities of daily living

severely disabled; that is, these people would require daily care for activities of living and assistance to walk. It is important to make this clear to individuals and families when consenting for hemicraniectomy to ensure that they would find this outcome acceptable.

A striking result of the pooled analysis was that the hemisphere involved did not influence results, confirming that infarction of the speech-dominant hemisphere does not preclude significant recovery and should not contraindicate decompression..$^{9,19}$ However all of the patients in the three pooled studies were aged 60 years or younger and a number of prior studies have suggested younger age may be a crucial determinant of better outcome..$^{9,20-22}$

\section{Uncertainties: Patient age, timing of surgery and cerebral imaging}

The positive results of early decompression for malignant infarction of the middle cerebral artery were found in a specific patient population undergoing a uniform operation, within a short time interval. The mean patient age and mean time to surgery in the DECIMAL, DESTINY and HAMLET (reported results to date) studies were: 43.4 years and 20.5 hours, 44.6 years and 24.4 hours, and 48.2 years and 29.5 hours (to randomization) respectively. Compared to the general patient population presenting with MCA stroke, patients enrolled in these studies were on average less than 50 years of age and surgery was performed prior to the clinical deterioration that usually prompts surgical consideration in the real world. While age past 60 or surgical delay beyond 48 hours should not necessarily contraindicate decompression surgery, it should be borne firmly in mind that the results from the pooled analysis in favour of surgery cannot be extrapolated to patients under these circumstances.

Imaging findings formed part of the inclusion criteria for all three randomized trials contributing to the pooled analysis, ${ }^{16}$ although the abnormal findings required for entry were not consistent between studies. DECIMAL had the most stringent imaging criterion requiring MRI scanning to demonstrate $>145$ $\mathrm{cm}^{3}$ of infarcted brain tissue, as measured on the diffusion weighted imaging (DWI) sequence. ${ }^{14}$ The mean infarct volume in the surgical group was $211.5 \mathrm{~cm}^{3}$ (range 146-381 $\mathrm{cm}^{3}$ ) and was similar to the medical group with respective figures of 214.7 $\mathrm{cm}^{3}$ (range 150-308 $\mathrm{cm}^{3}$ ). A subgroup analysis showed that DWI infarct volume at inclusion correlated positively and significantly with outcome (score on mRS) at six months in those treated without surgery. Indeed, no patient with a volume $>210$ $\mathrm{cm}^{3}$ at inclusion survived without craniectomy. Conversely the eight people screened but excluded from this trial due to infarct volumes $<145 \mathrm{~cm}^{3}$, all survived. A similar analysis in the surgical arm of DECIMAL also showed a trend towards worse outcome in patients with higher infarct volumes though this did not reach significance. This threshold of $145 \mathrm{~cm}^{3}$ DWI infarct volume has previously been demonstrated to be an accurate predictor for the development of malignant infarction in those presenting with MCA stroke and persistent arterial occlusion. ${ }^{23}$ However no study has yet confirmed this relationship between infarct volume and functional outcome following hemi-craniectomy. If the trend seen in DECIMAL could be established in a future study (i.e. establishing a threshold infarct volume beyond which patients do significantly worse despite surgery) then DWI infarct measurement could be used as an objective decider for surgical decompression. An important issue to consider in such a study would be exactly when this "deciding" MRI should be performed, given that DWI lesions evolve and may exceed the $145 \mathrm{~cm}^{3}$ barrier with time. ${ }^{24}$

The formation of fatal edema following MCA infarction has been predicted by other imaging studies. Early CT hypodensity involving $>50 \%$ of the MCA territory as well as involvement of additional vascular territories (namely anterior and posterior cerebral arteries) are associated with an increased risk of fatal brain edema. ${ }^{25}$ Such changes on initial CT scans were used as inclusion criteria in DESTINY ( $\geq 2 / 3$ MCA territory infarction 
including at least part of basal ganglia) and HAMLET ( $\geq 2 / 3$ MCA territory infarction and space-occupying edema), without the need for MRI to assess infarct volume. A case-control study that examined CT scans performed within 18 hours of stroke onset showed that loss of grey-white matter differentiation or attenuated corticomedullary contrast (as described by the authors), predicted the development of malignant middle cerebral artery infarct. ${ }^{26}$ Single-photon emission CT (SPECT) scanning can determine the extent of impaired cerebral blood flow following stroke and has also been studied as a prognostic indicator following MCA stroke. ${ }^{27}$ One hundred and eight patients were scanned prospectively within six hours of MCA stroke in order to determine the predictive value of SPECT in determining fatal ischemic edema compared with either CT findings or clinical examination alone. An activity deficit of the whole MCA territory was found to be highly accurate in predicting malignant MCA infarction and subsequent death. It is possible therefore that SPECT scanning could be used early after symptom onset to identify those at risk of fatal stroke, depending on the availability of this imaging modality.

Regarding the timing of surgical intervention, the argument for very early intervention is the notion that it might in itself limit damage caused by progressive swelling and mass effect. ${ }^{7,28,29}$ The counter-argument is that surgery may be over utilized, exposing patients who will not ultimately require it to the risks and morbidity of several major operations. At present, the optimal approach to this issue of timing is not clear.

In summary, imaging parameters have shown reasonable predictive value for the development of malignant middle cerebral artery infarction and may assist surgical decisionmaking. However the ideal imaging modality and its timing with respect to stroke onset to allow optimal patient selection for medical versus surgical treatment is not yet known. As the authors of the pooled analysis emphasize, the decision to perform decompression surgery can only be made on an individual basis in every single patient, considering patient age, neurological condition, and the CT or MRI imaging results available at the time. ${ }^{16}$

\section{Hemicraniectomy and duraplasty: Technical procedure}

Common to all three randomized trials discussed above was the creation of a large bone flap (including frontal, temporal and parietal bones, including bone removal to reach the floor of the middle cranial fossa) and expansion of the dural covering. A number of descriptions of hemicraniectomy have appeared in the literature in recent years, varying in bone flap size, handling of the dura mater and recommendation for storing excised skull. ${ }^{30-33}$ There is consensus that opening dura is imperative. Yoo et al demonstrated a two-step reduction in intracranial pressure during decompressive surgery; the first with bone flap removal and the second with dural opening. ${ }^{34}$ In our experience the most critical step following patient selection, is ensuring an adequately sized bone flap (see the Neuroimaging Highlight in this edition of the Journal). In addition to maximizing intracranial pressure reduction, there is evidence from experiments in animals that infarct size can be reduced by wide craniectomy and that its efficacy relates to the size of the decompression and the promptness with which it is carried out. ${ }^{28,29,35}$ The following is an illustrated description of the steps we have discovered useful in

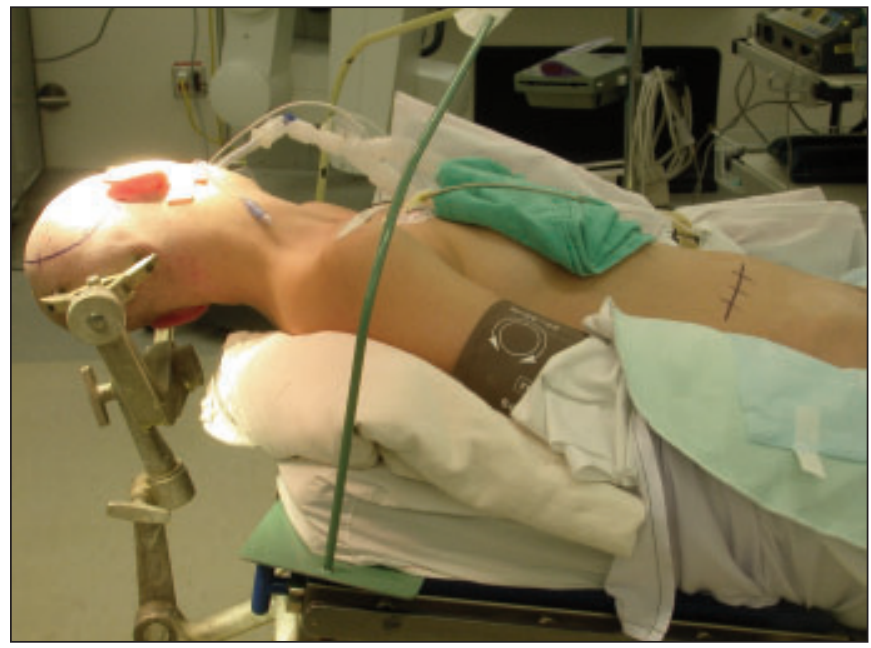

Figure 1: Patient position (see text for details).

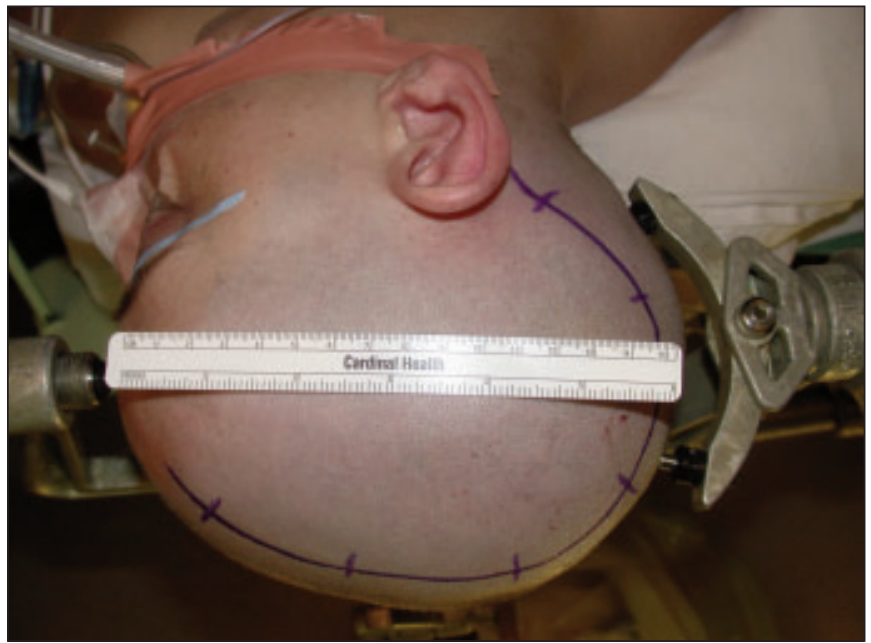

Figure 2: Scalp incision. (see text for details)

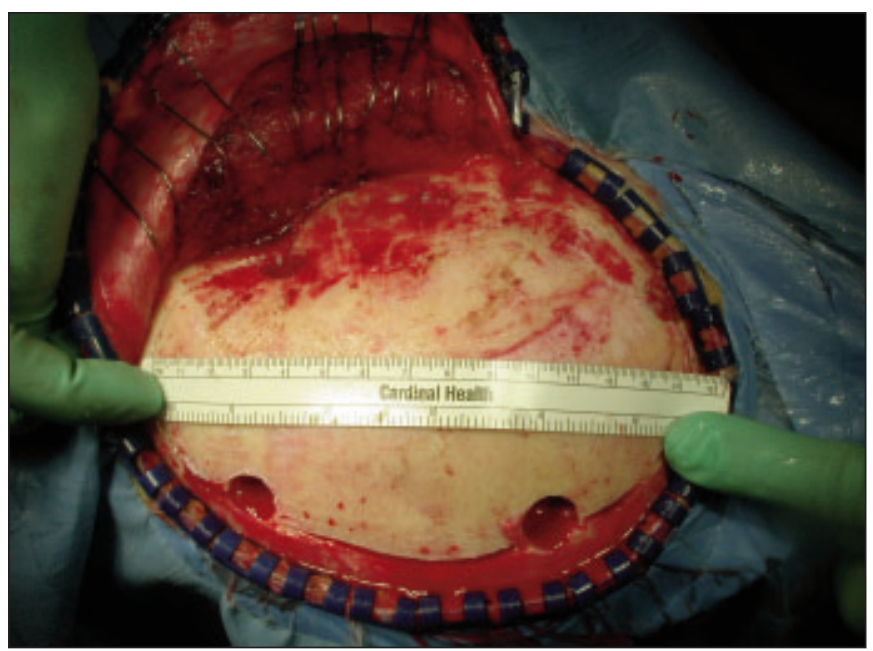

Figure 3: Bone flap (see text for details). 


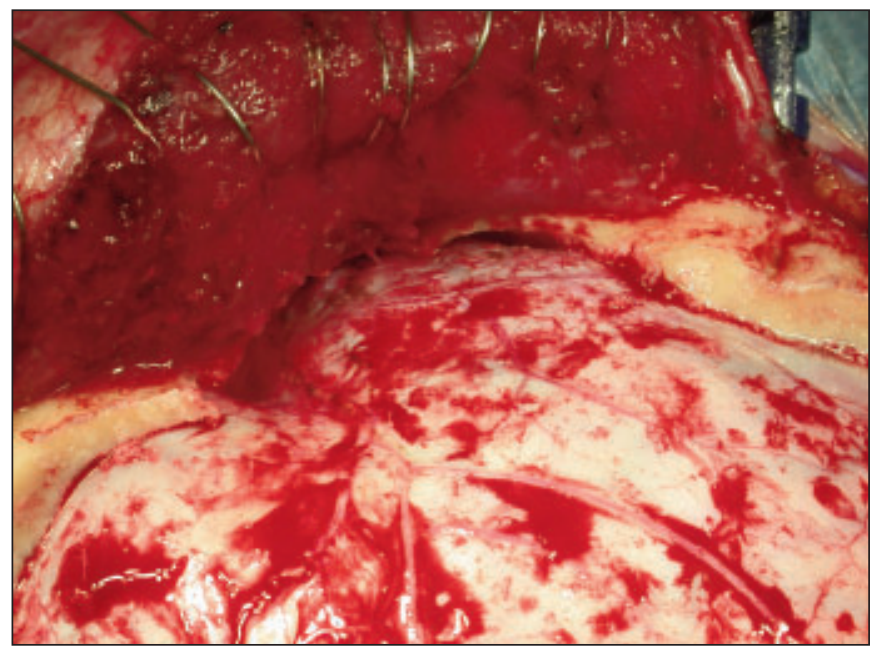

Figure 4: Subtemporal decompression (see text for details).

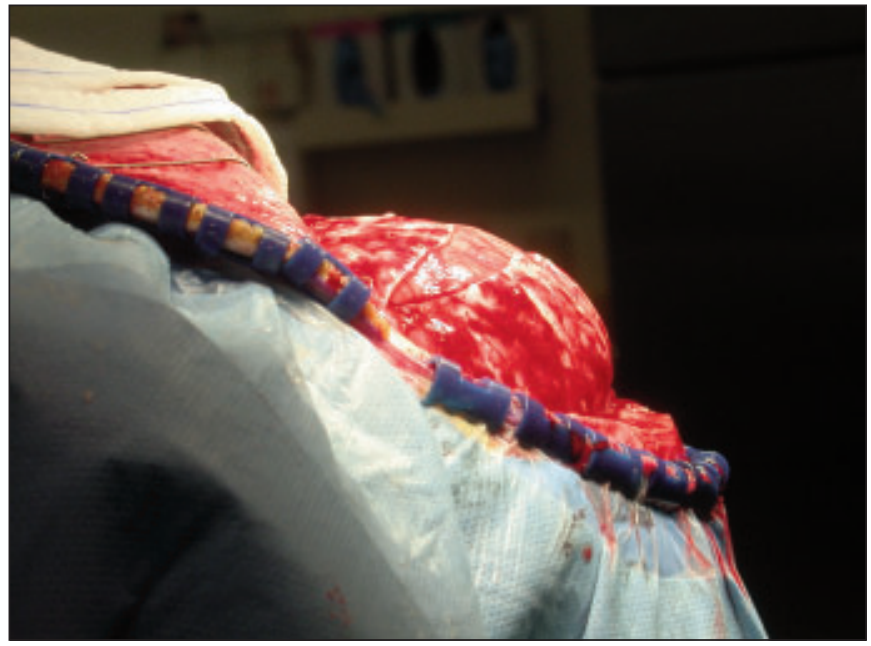

Figure 5: Dural opening (see text for details).

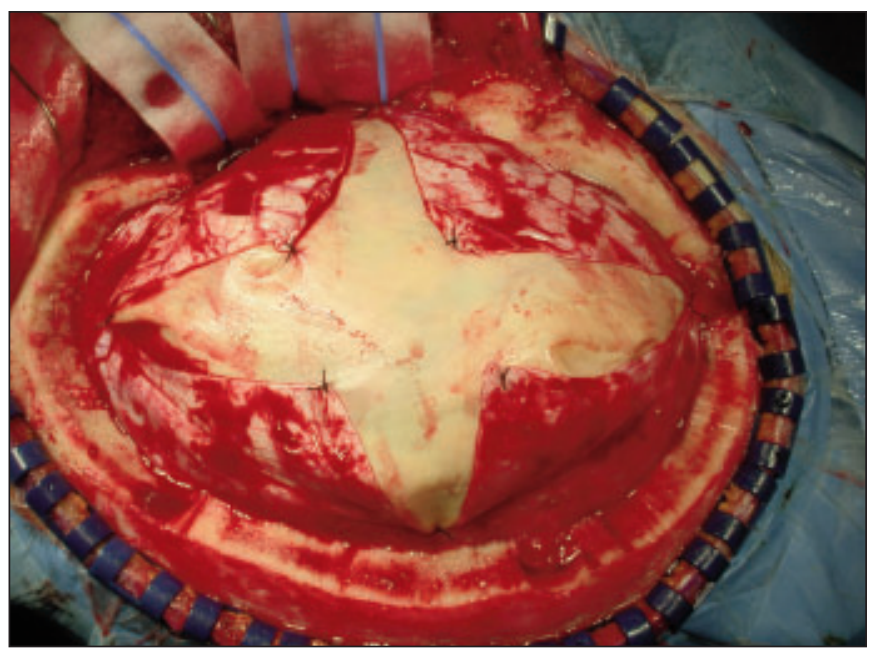

Figure 6: Duraplasty with bovine pericardium (see text for details). performing decompressive hemicraniectomy for malignant middle cerebral artery infarction.

The patient is positioned supine with a pad beneath the shoulder ipsilateral to the infarction, the head turned parallel to the floor, and the cranial vertex tilted approximately 15 degrees downward to allow access to the subtemporal region (Figure 1). ${ }^{1}$ A question mark (left hemisphere) or reverse question mark (right hemisphere) scalp incision is marked beginning behind the ear over the mastoid process, running along the midline over the sagittal sinus and ending at the hairline over the ipsilateral eye. The scalp flap should be approximately $16 \mathrm{~cm}$ long in an adult to allow for a $14 \mathrm{~cm}$ bone flap measured front to back, and it is useful to employ a ruler or tape measure to be sure of an adequately sized scalp flap (Figure 2 ). The free bone flap should include frontal, temporal, parietal, and occipital bones (Figure

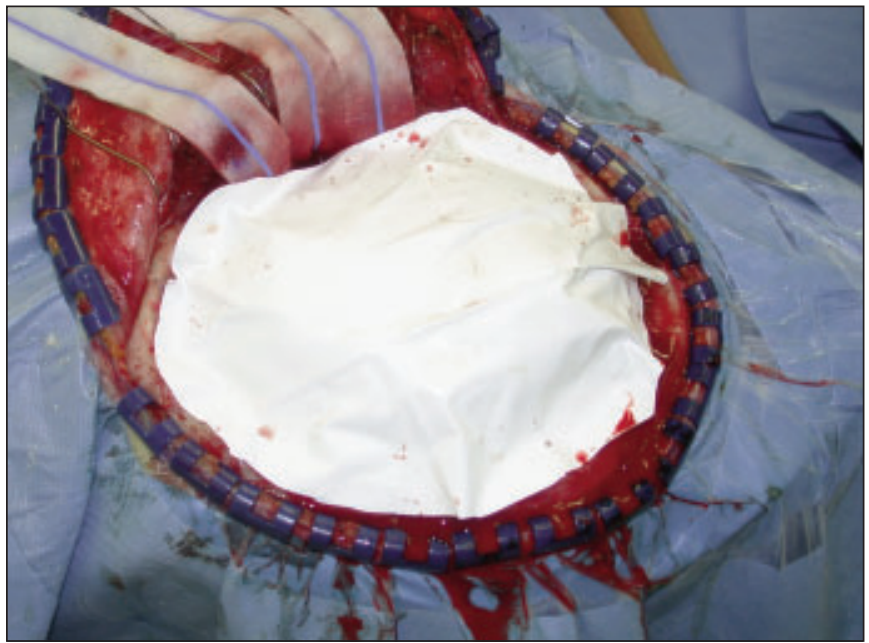

Figure 7: Positioning of Gortex membrane between duraplasty and galea (see text for details).

3), but to remain safe and avoid dural sinus injury, it should be carefully made superior to the transverse and lateral to the superior sagittal, dural venous sinuses. A flexible sterile ruler is very useful at this point to measure and mark the bone flap, avoiding an undersized opening. Depending on the size of the patient's head and MCA territory stroke it is possible that a smaller bone flap will suffice, but we have learned from our own experience, that a $14 \mathrm{~cm}$ bone flap from front to back (anteroposterior dimension) and bone removal 1 to $2 \mathrm{~cm}$ lateral to the sagittal suture reaching all the way down to the floor of the anterior cranial fossa at the level of the coronal suture (Figure 4) is usually required, and therefore now always performed.

Whenever possible we prefer to save the bone flap in the subcutaneous tissue of the right lower quadrant of the patient's 
abdomen (Figure 1). However we will often store this flap in the bone bank in order to avoid the morbidity of a large skull flap planted in the abdominal tissues, if a patient is particularly lean (as illustrated here). In our experience we find that culture of bone fragments retrieved from the excised flap unrewarding and therefore do not routinely perform this. Next, bone is removed by rongeur from the subtemporal region in order to reach the floor of the middle cranial fossa (Figure 3 ).

Dura is opened in a cruciate (referred to by some as "stellate") fashion allowing for brain herniation above the calvarium bordering the craniectomy (Figure 5). A bovine pericardium patch (Peri-Guard $\left.{ }^{\mathrm{R}}\right)^{2}$ makes an excellent dural patch, and a large oval piece can be cut from a $10 \mathrm{~cm}$ x $16 \mathrm{~cm}$ repair patch to lie beneath the patient's own dural flap directly on the pia mater. The four apices of the durotomy are tacked to the underlying patch and the tips of the dural flaps are pulled back slightly and also tacked to the underlying patch, allowing for some additional dural expansion (Figure 6).

Meticulous hemostasis of the galea and temporalis muscle is necessary. We have had one patient who despite placement of a subgaleal drainage tube developed a postoperative subgaleal hematoma resulting in uncal herniation and who required urgent surgical evacuation. A Gortex membrane (Preclude ${ }^{\mathrm{R}}$ pericardial membrane) ${ }^{3}$, cut to the shape of the bone flap (Figure 6) and placed between the duraplasty and galea (Figure 7) is extremely useful in preventing adhesions between those two layers. At the time of skull flap replacement, and up to months after the craniectomy procedure, the scalp and galea simply lift off this membrane which is then easily separated from the underlying dural repair. Use of a Gortex membrane greatly simplifies cranioplasty, a procedure typically carried out several months following decompression, when the brain is fully relaxed and the patient has begun to recover.

\section{CONCLUSION}

The hardest step in performing hemicraniectomy for stroke is deciding, along with families, patients themselves whenever possible and colleagues whether or not the procedure is appropriate for that particular patient. Not all patients with complete MCA infarction require surgical decompression to survive, and not all of those with life-threatening infarctions survive even with decompression. Clinical deterioration to lethargy combined with radiological evidence of significant midline shift and uncal herniation is an appropriate time to consider surgery. For patients who survive hemicraniectomy the road to their best level of recovery is very long and difficult, and can be enormously depressing. Most patients will remain permanently dependent on others for some aspects of their daily lives, so the presence of a supportive family capable of dealing with both the physical and psychological burdens their loved one will bring is crucial. While many neurosurgeons will remain skeptical of the value of decompression for brain infarction, the randomized trials to date have demonstrated that decompression in relatively young patients operated on before fixed brainstem dysfunction can not only prevent death but also allow for reasonable recovery in some patients who would otherwise die. To offer that hope, a radical decompression procedure is required, a version of which has been presented here.

\section{Disclosure}

1. Permission was obtained from the patient shown for use and publication of photographs taken at the time of her surgery.

2. Synovis Surgical Innovations, a division of Synovis Life Technologies, Inc., St. Paul MN, USA

3. W.L Gore \& Associates, Inc., Flagstaff, Arizona, USA

\section{REFERENCES}

1. Bounds JV, Wiebers DO, Whisnant JP, Okazaki H. Mechanisms and timing of deaths from cerebral infarction. Stroke. 1981;12: 474-7.

2. Hacke W, Schwab S, Horn M, Spranger M, De Georgia M, von Kummer R. "Malignant" middle cerebral artery territory infarction: Clinical course and prognostic signs. Arch Neurol. 1996;53:309-15.

3. Ivamoto HS, Numoto M, Donaghy RM. Surgical decompression for cerebral and cerebellar infarcts. Stroke. 1974;5:365-70.

4. Robertson SC, Lennarson P, Hasan DM, Traynelis VC. Clinical course and surgical management of massive cerebral infarction. Neurosurgery. 2004;55:55-62.

5. Rengachary SS, Batnitzky S, Morantz RA, Arjunan K, Jeffries B. Hemicraniectomy for acute massive cerebral infarction. Neurosurgery. 1981;8:321-8.

6. Rieke K, Schwab S, Krieger D, von Kummer R, Aschoff A, Schuchardt V, et al. Decompressive surgery in space-occupying hemispheric infarction: results of an open, prospective trial. Crit Care Med. 1995;23:1576-87.

7. Schwab S, Steiner T, Aschoff A, Schwarz S, Steiner HH, Jansen O, et al. Early hemicraniectomy in patients with complete middle cerebral artery infarction. Stroke. 1998;29:1888-93.

8. Hacke W, Schwab S, Horn M, Spranger M, De Georgia M, von Kummer R. "malignant" middle cerebral artery infarction: clinical course and prognostic signs. Arch Neurol. 1996;53: 309-15.

9. Gupta R, Connolly ES, Mayer S, Elkind MS. Hemicraniectomy for massive middle cerebral artery territory infarction: a systematic review. Stroke. 2004;35:539-43.

10. Wijdicks EFM. Hemicraniotomy in massive hemispheric stroke: a stark perspective on a radical procedure. Can J Neurol Sci. 2000;27:271-3.

11. Demchuk AM. Hemicraniectomy is a promising treatment in ischemic stroke. Can J Neurol Sci. 2000;27:274-7

12. Frank JI. Hemicraniectomy and durotomy upon deterioration from infarction related swelling trial (HeaDDFIRST): first public presentation of the primary study findings. Neurology. 2003;60 Suppl 1:A426.

13. Juttler E, Schwab S, Schmiedek P, Unterberg A, Hennerici M, Woitzik J, et al. Decompressive surgery for the treatment of malignant infarction of the middle cerebral artery (DESTINY): a randomized, controlled trial. Stroke. 2007;38:2518-25.

14. Vahedi K, Vicaut E, Mateo J, Kurtz A, Orabi M, Guichard JP, et al. Sequential-design, multicenter, randomized, controlled trial of early decompressive craniectomy in malignant middle cerebral artery infarction (DECIMAL Trial). Stroke. 2007;38:2506-17.

15. Hofmeijer J, Amelink GJ, Algra A, van Gijn J, Macleod MR, Kappelle LJ, et al. Hemicraniectomy after middle cerebral artery infarction with life-threatening Edema trial (HAMLET). Protocol for a randomised controlled trial of decompressive surgery in space-occupying hemispheric infarction. Trials. 2006;7:29.

16. Vahedi K, Hofmeijer J, Juettler E, Vicaut E, George B, Algra A, et al. Early decompressive surgery in malignant infarction of the middle cerebral artery: a pooled analysis of three randomised controlled trials. Lancet Neurol. 2007;6:215-22.

17. van Swieten JC, Koudstaal PJ, Visser MC, Schouten HJ, van Gijn J. Interobserver agreement for the assessment of handicap in stroke patients. Stroke. 1988;19(5):604-7.

18. Mayer SA. Hemicraniectomy: a second chance on life for patients with space-occupying MCA infarction. Stroke. 2007;38:2410-2. 
19. Kastrau F, Wolter M, Huber W, Block F. Recovery from aphasia after hemicraniectomy for infarction of the speech-dominant hemisphere. Stroke. 2005;36:825-9.

20. Foerch C, Lang JM, Krause J, Raabe A, Sitzer M, Seifert V, et al. Functional impairment, disability and quality of life outcome after decompressive hemicraniectomy in malignant middle cerebral artery infarction: J Neurosurg. 2004;101:248-54.

21. Curry WT, Sethi MK, Ogilvy CS, Carter BS. Factors associated with outcome after hemicraniectomy for large middle cerebral artery territory infarction. Neurosurgery. 2005;56:681-92.

22. Pillai A, Menon SK, Kumar S, Rajeev K, Kumar A, Panikar D. Decompressive hemicraniectomy in malignant middle cerebral artery infarction: an analysis of long-term outcome and factors in patient selection. J Neurosurg. 2007;106:59-65.

23. Oppenheim C, Samson Y, Manai R, Vandamme X, Crozier S, Cornu $\mathrm{P}$, et al. Prediction of malignant middle cerebral artery infarction by diffusion-weighted imaging. Stroke. 2000;31: 2175-81.

24. Neumann-Haefelin T, Sitzer M, du Mesnil de Rochemont R, Lanfermann H. Prediction of malignant MCA infarction with DWI: pitfalls in hyperacute stroke. Stroke. 2001;32:580-3.

25. Kasner SE, Demchuk AM, Berrouschot J, Schmutzhard E, Harms $\mathrm{L}$, Verro $\mathrm{P}$, et al. Predictors of fatal brain edema in massive hemispheric ischemic stroke. Stroke. 2001;32:2117-23.

26. Haring HP, Dilitz E, Pallua A, Hessenberger G, Kampfl A, Pfausler $\mathrm{B}$, et al. Attenuated corticomedullary contrast: an early cerebral computed tomography sign indicating malignant middle cerebral artery infarction. A case-control study. Stroke. 1999;30:1076-82.

27. Berrouschot J, Barthel H, von Kummer R, Knapp WH, Hesse S, Schneider D. $99 \mathrm{~m}$ technetium-ethyl-cysteinate-dimer singlephoton emission CT can predict fatal ischemic brain edema. Stroke. 1998;29:2556-62.
28. Forsting M, Reith W, Schäbitz WR, Heiland S, von Kummer R, Hacke W, et al. Decompressive craniectomy for cerebral infarction: an experimental study in rats. Stroke. 1995;26: 259-64.

29. Doerfler A, Forsting M, Reith W, Staff C, Heiland S, Schäbitz WR, et al. Decompressive craniectomy in a rat model of "malignant" cerebral hemispheric stroke: experimental support for an aggressive therapeutic approach. J Neurosurg. 1996;85:853-9.

30. Mitchell P, Tseng M, Mendelow AD. Decompressive craniectomy with lattice duraplasty. Technical note. Acta Neurochir(Wien). 2004; 146:159-60.

31. Holland M, Nakaji P. Craniectomy: surgical indications and technique. Operative techniques in neurosurgery. 2004;7:10-15.

32. Schneck MJ, Origitano TC. Hemicraniectomy and durotomy for malignant middle cerebral artery infarction. Neurol Clin. 2006; 24:715-27.

33. Hutchinson P, Timofeez I, Kirkpatrick P. Surgery for brain edema. Neurosurg Focus. 2007;22:E14.

34. Yoo DS, Kim DS, Cho KS, Huh PW, Park CK, Kang JK. Ventricular pressure monitoring during bilateral decompression with dural expansion. J Neurosurg. 1999;91:953-9.

35. Engelhorn T, Doerfler A, Kastrup A, Beaulieu C, de Crespigny A, Forsting M, et al. Decompressive craniectomy, reperfusion, or a combination for early treatment of acute "malignant" cerebral hemispheric stroke in rats? Potential mechanisms studied by MRI. Stroke. 1999;30:1456-63. 